\title{
Potentiometric and Conductometric Studies on Complexes of Folic Acid with some Metal Ions
}

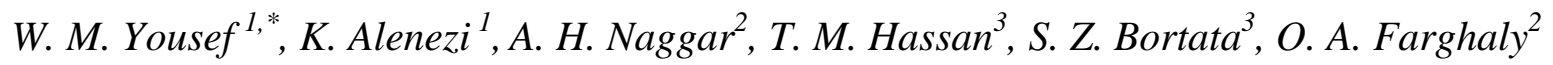 \\ ${ }^{1}$ Chemistry Department, Faculty of Science, Hail University, Saudi Arabia. \\ ${ }^{2}$ Chemistry Department, Faculty of Science, Al-Azhar University, Assiut Branch, 71524, Assiut, \\ Egypt. \\ ${ }^{3}$ Chemistry Department, Faculty of Science, Sebha University, Sebha, Libya \\ *E-mail: wafaa_youssef95@ hotmail.com
}

doi: $10.20964 / 2017.02 .06$

Received: 10 October 2016 / Accepted: 23 November 2016 / Published: 30 December 2016

\begin{abstract}
Sixteen metal ions viz; $\mathrm{Li}$ (I), Mg (II), $\mathrm{Sr}$ (II), Ca (II), Mn (II), Co (II), Ni (II), Cu (II), Zn (II), Cd (II), $\mathrm{Ba}$ (II), $\mathrm{Pb}$ (II), Al (III), Cr (III), Fe (III) and Th (IV) were selected to elucidate their interaction with folic acid using potentiometric method. The protonation and stability constants of formed complexes have been calculated using ionic strength, $\mathrm{I}=0.2 \mathrm{M} \mathrm{NaNO}_{3}$ in aqueous solutions at $25 \pm 0.1{ }^{\circ} \mathrm{C}$. Complexes of 1:1, 1:2 and/or 1:3 metal to ligand ratios were formed depending on the nature of the ligand or metal ions. The order of stability constants of the binary complexes was examined. The stiochiometry of the formed complexes was confirmed by conductometric method. Also, the ionic equilibria of ligand and its complexes with different metal ions in solution were investigated.
\end{abstract}

Keywords: Folic acid, metal complexes, potentiometry, conductometry

\section{FULL TEXT}

(C) 2017 The Authors. Published by ESG (www.electrochemsci.org). This article is an open access article distributed under the terms and conditions of the Creative Commons Attribution license (http://creativecommons.org/licenses/by/4.0/). 